\title{
Sinais comportamentais precoces no contexto da pesquisa e da clinica infantil em um caso de suspeita de transtorno psicótico
}

\author{
Early behavioral signs in the context of research and child's \\ clinical in a case of suspected psychotic disorder
}

Andréa Carla Machado ${ }^{1}$

\section{Resumo}

A maioria dos adultos com transtorno psiquiátrico atendeu primeiro aos critérios de diagnóstico durante a infância e / ou a adolescência, mas padrões de previsão homotípicos e heterotípicos específicos e mesmo os sintomas prodrômicos não foram firmemente estabelecidos devido a ausência de informações pregressas bem fundamentadas para os acompanhamentos posteriores. Assim, a observação de um profissional se faz essencial, lançando mão de recursos e protocolos importantes, principalmente na etapa do desenvolvimento infantil. O objetivo do presente texto foi relatar os sintomas comportamentais precoce de um caso de suspeita de transtorno psicótico na infância. São descritos os comportamentos precoces no contexto clínico, na escola e no ambiente familiar de um menino de cinco anos e seis meses de idade cursando a pré-escola de uma instituição privada de uma cidade do interior do Estado de São Paulo. Os dados foram coletados por meio de observação direta com roteiro pré-estabelecido pela profissional e utilizado com a família e escola os instrumentos CBCL (6-18) e EACI-P. Pode-se observar que os comportamentos indicados pelos contextos (clinico, família e escola) direcionam para um perfil clínico com características que compõem

\footnotetext{
${ }^{1}$ Linguista, Pedagoga, Mestre e Doutora em Educacão Especial. Pós-Doutora em Psicologia (UFSCar) Educacão (UNESP). Pesquisadora e Psicopedagoga clínica no Centro de Pesquisa e Desenvolvimento Infantil, CPED

Interfaces da Educ., Paranaíba, v.11, n.31, p. 582 - 605, 2020
} 
um quadro de transtorno psicótico, sendo importante esses apontamentos para auxiliar a área psiquiátrica na conduta diagnóstica.

Palavras-chave: Transtornos mentais. Intervenção precoce. Pródromo. Infância.

\section{Abstract}

Most adults with psychiatric disorder first met the diagnostic criteria during childhood and/or adolescence, but specific homotypical and heterotypical prediction patterns and symptoms were not firmly established due to the absence of well-founded and systematically past information for later followups. In this perspective, the observation of a professional is essential, using important resources and protocols, especially in the stage of child development. Then of this text was to report the early behavioral symptoms of a case of suspected psychotic disorder in childhood. Early behaviors are described in the clinical context, in school and in the family environment a five-year-old boy and six months old attending the preschool of a private institution in a city in the interior of the Sao Paulo State. Data were collected through direct observation with a script pre-established by the professional and used with the family and school the CBCL instruments (6-18) and EACIP. It can be observed that the behaviors indicated by the contexts (clinic, family and school) direct to a clinical profile with characteristics that make up a picture of psychotic disorder, and these notes are important to assist the psychiatric area in the diagnostic conduct.

Keywords: Mental disorders. Early intervention. Prodrome. Childhood.

\section{Introdução}

O desenvolvimento pode ser visto como um processo progressivo no qual a criança cresce em direção a um desfecho que podemos chamar de maturidade? Quanto do que você é hoje poderia ter sido moldado pelo seu background genético e quanto seria mais bem explicado como resultado das suas experiências de vida? E ainda, o ditado "a prática leva à perfeição" tão Interfaces da Educ., Paranaíba, v.11, n.31, p. 582 - 605, 2020 
utilizado no cotidiano para estimular a aprendizagem de todo iniciante exprime a ideia de que repetindo, treinando e praticando tudo pode ser aprendido.

Inicia-se esse texto com perguntas e premissas (MACCOBY, 2000), as quais servirão como curso para o desenvolvimento do tema do presente artigo. Atualmente, o entendimento de que o desenvolvimento humano envolve uma complexa interação ao longo do tempo, tanto de aspectos genéticos (e outros muito biológicos) quanto de fatores ambientais postularam em evidência cientificas (COSTA; MALLOY-DINIZ; MIRANDA, 2018) mais recentes sobre influências genéticas, que ajudam sobre maneira a moldar o desenvolvimento infantil.

Nessa perspectiva, há a questão que diz respeito diretamente ao desenvolvimento do cérebro humano, o qual há conexões sinápticas e circuitos neurais que são moldados continuamente para maximizar sua adaptação. Assim, o conceito de interação gene-ambiente deriva, estritamente de estudos quantitativos, no entanto é mister considerar esses resultados (COSTA; MALLOY-DINIZ; MIRANDA, 2018) dentro de um contexto dinâmico adaptativo ao contexto e ao tempo. Essas ideias de interação-ambiente têm dado lugar ao estudo da epigenética.

Epigenética se refere aos mecanismos pelos quais as células são alteradas em forma e função e depois transmitem essas alterações para futuras células daquela linhagem (SANTANA; SOUZA, 2018). Portanto, em reposta a estímulos externos/do ambiente, os genes são "ativados" ou "desativados" à medida que o organismo vai passando pela vida e assim, a epigenética é um dos fenômenos que nos ajuda a entender como um mesmo genótipo pode potencialmente se expressar nos mais diversos fenótipos, cuja características intermediárias que possam se apresentar são chamadas de endofenótipos.

No caso dos transtornos mentais, por exemplo, uma cadeia de influência poderia ocorrer com aumento do nível de complexidade: gene - efeitos moleculares e celulares - impacto em circuitos neurais - alterações de sistema neural - características cognitivas e comportamentais - transtorno (KARAYORGOU; SIMON; GOGOS, 2010) como o desenvolvimento de Interfaces da Educ., Paranaíba, v.11, n.31, p. 582 - 605, 2020 
psicopatologias, por exemplo, um modelo de vulnerabilidade. Esse modelo multicausal pressupõe que o desenvolvimento de um transtorno mental se daria quando um perfil específico de vulnerabilidade (exemplo, traços genéticos, ou biológicos) interage com influências ambientais ou estressores (um evento ou situação ou uma série de eventos de vida que perturbam o equilíbrio psicológico de uma pessoa). (SIGELMAN; RIDER, 2009). Isso significa que uma gama de diferenças individuais entre as pessoas as tornaria mais ou menos vulneráveis a desfechos específicos, como os transtornos mentais.

\section{Referencial teórico}

\section{Espetro de habilidades e funcionamento dos transtornos mentais.}

Muitos transtornos mentais apresentam, em certa medida, uma janela de vulnerabilidade durante a qual o individuo tem maiores chances de desenvolver certo transtorno, e outros não. A maior parte começa na infância, com aproximadamente dois terços adultos afetados tendo exibido sinais de seu transtorno mais cedo no ciclo vital (COPELAND, et, al., 2009).

Os transtornos mentais podem ser distinguidos segundo sua trajetória de desenvolvimento, e cada grupo de transtornos envolve sinais e sintomas particulares, expressos também em periodos particulares do desenvolvimento com perfis únicos de fatores de risco correspondentes (PINE; FOX, 2015). Em termos de transtornos mentais com fortes antecedentes na infância, três formas têm sido mais bem estudadas: a-) do neurodesenvolvimento (transtorno do espectro do autismo, transtorno de déficit de atenção/hiperatividade); b-) psicóticos (esquizofrenia); c-) emocionais (depressão, pânico, transtorno de ansiedade social dentro outros).

Esses transtornos têm características comuns. Por exemplo, os transtornos de neurodesenvolvimento e os psicóticos tem fortes bases genéticas, enquanto os psicóticos e emocionais apresentam mudanças particulares de expressão após uma determinada idade (puberdade). Assim, em sua revisão sobre os antecedentes infantis dos transtornos mentais, Pine

e Fox (2015) descreveram cinco características de cada grupo (neurodesenvolvimento, psicóticos e emocionais) com implicação sobre a Interfaces da Educ., Paranaíba, v.11, n.31, p. 582 - 605, 2020 
decisão da intervenção precoce, ainda na infância, sobre os primeiros sinais de risco, a saber: manifestação de sintomas (pródromo); desenvolvimento (atraso, trajetória, apresentação); diferença de sexo (predominante); marcadores precoces e intervenção precoce (foco nos marcadores, antes da manifestação completa) e completam que a despeito das diferenças na força de associação com fatores de risco de origem genética ou ambiental, nesse ponto do conhecimento, já é sabido que a intervenção precoce, na infância mesmo, é fundamental para impedir ou, ao menos, amenizar desfechos pouco adaptativos/negativos relacionados aos transtornos mentais.

Nessa direção, no presente artigo será apresentado sinais comportamentais precoces observados em um conjunto de sintomas denominado de pródromo a respeito de um caso de suspeito de transtorno psicótico na infância.

Embora os tratamentos estejam melhorando gradualmente, o curso da doença para pacientes com transtornos psicóticos é frequentemente marcado por várias hospitalizações e uma vida inteira de prescrições de medicamentos antipsicóticos. Como o campo está longe de ser uma "cura" para tais transtornos psicóticos, o avanço da prevenção e da intervenção precoce é vital para melhorar os déficits funcionais. A identificação das pessoas com maior risco de desenvolver um transtorno psicótico é um passo crucial (PINE; FOX, 2015; BORA; MURRAY, 2013).

Assim, no contexto da clínica psicopedagógica infantil há um importante componente, a observação e a descrição de sinais e sintomas que podem auxiliar de uma forma singular na conduta e no acompanhamento do quadro de um paciente para outros profissionais que se fazem essenciais no diagnóstico do transtorno psiquiátrico, como por exemplo, o psiquiatra infantil.

O início da psicose pode ser precedido por semanas, meses ou anos de anormalidades psicológicas e comportamentais, incluindo distúrbios na cognição, emoção, percepção, comunicação, motivação e sono. $\mathrm{O}$ desenvolvimento incipiente desses sintomas permite que os clínicos e pesquisadores identifiquem aqueles com maior risco de conversão para um 
transtorno psicótico, proporcionando assim uma oportunidade única para pesquisas sobre tratamento precoce.

Os pesquisadores também tentaram descrever o curso do pródromo. As evidências sugerem que o curso a seguir é normalmente observado (BUTLER ; SCHECHTER; ZEMON, 2001; GREEN; NUECHTERLEIN; MINTZ, 1994). Primeiro, os indivíduos geralmente apresentam sintomas clinicos negativos ou inespecíficos, como depressão, sintomas de ansiedade, isolamento social e insucesso escolar. Isso geralmente é seguido pelo surgimento de sintomas básicos, sintomas positivos atenuados breves e intermitentes de intensidade moderada.

Mais proximal à psicose, os indivíduos geralmente apresentam comportamentos mais graves que permanecem subpsicóticos em termos de frequência (uma ou duas vezes por mês), duração (geralmente durando apenas alguns minutos e geralmente menos de um dia) e intensidade (ceticismo quanto à veracidade) de alucinações ou delírios ainda podem ser induzidos (BUTLER; SCHECHTER; ZENON, 2001). Durante esse período final de alto risco, os indivíduos geralmente exibem pensamentos incomuns pré-ilusórios, anormalidades perceptivas pré-alucinatórias ou distúrbios de fala desordenada, discurso desconexo.

$\mathrm{O}$ fato desses sintomas e experiências impactarem negativamente $\mathrm{o}$ desenvolvimento social, emocional e cognitivo torna a detecção e intervenção precoces especialmente importantes.

O período de sinais e sintomas subclínicos que precede o início da psicose é chamado de pródromo. O período prodrômico pode durar de semanas a vários anos e transtornos comórbidos são muito comuns nesse período (DICKSON, et al., 2018). O pródromo da esquizofrenia, por exemplo, e outros transtornos psicóticos é caracterizado como um processo de alterações ou deterioração de sintomas subjetivos e comportamentais heterogêneos que precedem o início dos sintomas psicóticos clínicos.

Indivíduos prodrômicos são frequentemente adolescentes e adultos jovens e muitas vezes na infância (GOULDING, 2013) experimentando distúrbios leves ou moderados na percepção, cognição, linguagem, função motora, vontade, iniciativa, nivel de energia e tolerância ao estresse Interfaces da Educ., Paranaíba, v.11, n.31, p. 582 - 605, 2020 
(ADDINGTON, et. al. 2019) Esse período de distúrbio pré-psicótico, no qual' características psicóticas atenuadas ou sublimiares começam a se manifestar, difere das características psicóticas francas em intensidade, frequência e / ou duração. O limiar, embora relativamente subjetivo e arbitrário, baseia-se na gravidade dos sintomas e na presença de sintomas psicóticos francos, o que justificaria tratamento medicamentoso antipsicótico imediato, significando o ponto final do período prodrômico (RIECHER-ROSSLER; STUDERUS, 2017). Embora o pródromo tenha sido visto tradicionalmente como uma construção retrospectiva, estão em andamento esforços para identificar e caracterizar o período prodrômico prospectivamente.

Embora o atendimento aos critérios prodrômicos estabelecidos seja o melhor preditor único de psicose futura (três a quatro vezes maior que o histórico familiar de psicose sozinho), pesquisas adicionais são necessárias para desenvolver algoritmos com utilidade preditiva aprimorada que permita entender melhor os mecanismos de psicose, progressão da doença e destacar possíveis intervenções para prevenir ou impedir o desenvolvimento de um distúrbio psicótico (BORA, 2015; MALDONADO, 2018).

No entanto, um subgrupo de pacientes com esquizofrenia apresenta um declínio funcional claro durante um período que se inicia desde alguns anos antes do início da psicose até alguns anos após o primeiro episódio, o qual pode ser observado na infância (LARSON; ALKER; COMPTON, 2010;). Algumas abordagens (CONDRAY; GLASGOW 2003(a); CONDRAY; STEINHAUER, 2003(b); CONDRAY, 2002), anormalidades pré-mórbidas foram relatadas para o funcionamento acadêmico e social.

Embora os pacientes com transtorno psicótico tenham um ano de escolaridade um pouco menor, essas diferenças geralmente não são significativas e geralmente variam em menos de um ano, comparado ao pares da mesma idade/escolaridade. Então, o padrão de funcionamento social em pessoas com transtornos psicóticos desde a infância até o início do quadro especificamente, não é claro, embora padrões diferenciais seria esperado um declínio acadêmico e social (CONDRAY; GLASGOW 2003(a); CONDRAY; STEINHAUER, 2003(b)). 
Dito isso, na clínica psicopedagógica infantil, também é o lugar de se observar de forma ecológica o paciente, já que há a oportunidade do oferecimento de diferentes nuances devido as diversas simulações de situações.

Segundo Rocha, Tafla e Texeira (2018) comportamentos são rotulados como "problemas" quando ocorrem em frequência e/ou intensidade elevadas ou muito baixas em relação a uma norma social ou de aprendizagem. Podem ser considerados problemáticos por impedirem ou dificultarem o acesso da criança a novas fontes de reforçamento que são importantes para que ela aprenda e se desenvolva. Dessa forma, entende-se que um comportamento é considerado um problema não necessariamente em razão de sua topografia, mas do impacto que ele causa no ambiente e da maneira como as pessoas do meio no qual a criança vive o percebem e o avaliam.

Nesse sentido, os objetivos de uma avaliação de problemas de comportamentos em crianças de idade pré-escolar são compreender a queixa do encaminhamento e identificar déficits e competências comportamentais da criança, para assim elaborar intervenções preventivas e/ou remediativas, a depender do tipo de problema verificado.

É importante salientar que diversos problemas de comportamento correspondem a dificuldades emocionais e comportamentais transitória e esperadas dentro dos marcos do desenvolvimento. Já outros, por sua intensidade e/ou frequência, demandam avaliação mais detalhada para descartar a presença de transtornos do neurodesenvolvimento e outros transtornos psiquiátricos que precisam de intervenções específicas. Dessa forma, uma característica importante para o clínico infantil é ter bom conhecimento sobre marcos esperados de desenvolvimento infantil, bem como de sinais e sintomas correlatos a problemas comportamentais que podem surgir em cada uma das fases do desenvolvimento. Essas variáveis precisam ser consideradas no processo de avaliação e na escolha da intervenção.

Nessa perspectiva, torna-se primordial o profissional fazer uma organização da observação comportamental dos sinais precoces e do desenvolvimento da aprendizagem do paciente a ser avaliado. Assim, o objetivo da presente pesquisa foi relatar os sintomas comportamentais Interfaces da Educ., Paranaíba, v.11, n.31, p. 582 - 605, 2020 
precoce de um caso de suspeita de transtorno psicótico na infância. São descritos os comportamentos precoces no contexto clínico, na escola e no ambiente familiar de um menino de cinco anos e seis meses de idade cursando a pré-escola.

\section{Delineamento metodológico sobre o caso clínico}

A escolha deste caso se deve principalmente a dois motivos. A primeira é de que o sujeito se apresenta como um paciente representativo dos sintomas pródromo com manifestações comportamentais subclinicas importantes na etapa da infância, em relação a um suspeito quadro psicótico. A segunda razão é que apesar da gravidade do quadro, há possibilidade da montagem de um programa de intervenção sistemático para auxiliar desenvolvimento da sua aprendizagem.

Arthur ${ }^{2}$, uma criança com 5 anos e 6 meses, sexo masculino, aluno da pré-escola de uma escola privada do interior do Estado de São Paulo. Segundo filho da progenitora, cujo primeiro com 23 anos de idade (apresentou e ainda persistem problemas de condutas comportamentais durante 0 desenvolvimento) é oriundo de outro relacionamento. De acordo com a mãe a criança não apresentou intercorrências no desenvolvimento. No entanto, durante o período gestacional disse ter passado por períodos conturbados, emocionalmente. Avó materna com perturbações e desajustes comportamentais e também em outros casos familiais. A criança precisou realizar cirurgia de freno (prega), com atraso (início com 24 meses) na fala. Arthur não é seletivo para se alimentar, mas em um período apresentou organização/restrita com objetos. É desorganizado, latência nas respostas (evocação tardia). A mãe aponta que a criança é desligada, fala demasiadamente (dificuldades controle inibitório) em situações de brincadeira e contexto social. Dificuldade práxica (ampla e fina) apresentando tremores nas maõs.

De acordo com Inventários do ASEBA (Achenbach System of Empirically Based Assessment) (ACHENBACH, 2010) especificamente o Inventário de comportamento para crianças - CBCL (C- TRF - 1 e $1 / 2$ a 5 anos) - pais

\footnotetext{
2 Nome fictício.
}

Interfaces da Educ., Paranaiba, v.11, n.31, p. 582 - 605, 2020 
(referencias) CBCL aplicado com a mãe foram levantados os seguintes apontamentos, a saber:

Quadro 1. Apresentação dos comportamentos de Arthur de acordo com a observação da mãe.

\begin{tabular}{|c|c|c|}
\hline Comportamentos & $\begin{array}{l}\text { Habilidades } \\
\text { prejudicadas }\end{array}$ & $\begin{array}{c}\text { Áreas cerebrais } \\
\text { requisitadas }\end{array}$ \\
\hline $\begin{array}{l}\text { Dificuldades em prestar a } \\
\text { atenção e manter atenção } \\
\text { compartilhada }\end{array}$ & $\begin{array}{l}\text { Apontamento de } \\
\text { funções executivas } \\
\text { não performantes } \\
\text { (Memória operacional } \\
\text { e atenção sustentada) }\end{array}$ & $\begin{array}{l}\text { Córtex pré- } \\
\text { frontal } \\
\text { dorsolateral } \\
\text { Córtex parietal } \\
\text { inferior }\end{array}$ \\
\hline Restrições/perseverações & $\begin{array}{l}\text { Percepção } \\
\text { prejudicada }\end{array}$ & $\begin{array}{l}\text { Corpo estriado } \\
\text { ventral }\end{array}$ \\
\hline Dificuldades perceptivas & $\begin{array}{l}\text { Percepção } \\
\text { prejudicada }\end{array}$ & $\begin{array}{l}\text { Corpo estriado } \\
\text { ventral }\end{array}$ \\
\hline $\begin{array}{lll}\text { Dificuldade } & & \text { de } \\
\text { autojulgamento (não } & \text { se } \\
\text { arrepende) } & & \end{array}$ & $\begin{array}{l}\text { Julgamento } \\
\text { moral/social } \\
\text { prejudicado } \\
\text { frontal) - } \quad \text { porções } \\
\text { anteriores. }\end{array}$ & $\begin{array}{l}\text { Córtex pré- } \\
\text { frontal medial } \\
\text { Córtex } \\
\text { temporoparietal } \\
\text { Amigdala }\end{array}$ \\
\hline $\begin{array}{l}\text { Dificuldades em seguir } \\
\text { regras }\end{array}$ & Não as compreende & $\begin{array}{l}\text { Córtex } \\
\text { dorsolateral } \\
\text { Formação } \\
\text { hipocampal }\end{array}$ \\
\hline Medos (escola) & Interação social & $\begin{array}{l}\text { Córtex pré- } \\
\text { frontal medial } \\
\text { Córtex } \\
\text { temporoparietal } \\
\text { Amigdala }\end{array}$ \\
\hline
\end{tabular}




\begin{tabular}{|c|c|c|}
\hline Mania de perseguição & Interacão social & $\begin{array}{l}\text { Córtex pré- } \\
\text { frontal medial } \\
\text { Córtex } \\
\text { temporoparietal } \\
\text { Amígdala }\end{array}$ \\
\hline Age impulsivamente & $\begin{array}{l}\text { Não programa suas } \\
\text { ações; } \quad \text { Controle } \\
\text { inibitório }\end{array}$ & $\begin{array}{ll}\text { Corpo estriado } \\
\text { ventral } \\
\text { Córtex } \\
\text { frontal }\end{array}$ \\
\hline $\begin{array}{l}\text { Irrita-se e fica nervoso, } \\
\text { tenso }\end{array}$ & Falta de controle & $\begin{array}{l}\text { Corpo estriado } \\
\text { ventral } \\
\text { Córtex pré- } \\
\text { frontal }\end{array}$ \\
\hline Reclama de cansaço & Sobrecarga, fadiga & $\begin{array}{l}\text { Corpo estriado } \\
\text { ventral }\end{array}$ \\
\hline Distrai-se facilmente & $\begin{array}{l}\text { Atenção sustentada } \\
\text { (baixa) }\end{array}$ & $\begin{array}{l}\text { Córtex pré- } \\
\text { frontal anterior }\end{array}$ \\
\hline Teimoso & Compreensão & $\begin{array}{l}\text { Formação } \\
\text { hipocampal }\end{array}$ \\
\hline Fala demasiadamente & $\begin{array}{l}\text { Discurso desconexo, } \\
\text { assuntos incoerentes }\end{array}$ & $\begin{array}{l}\text { Cortex } \\
\text { relacionados } \\
\text { com processos } \\
\text { auditivo e da } \\
\text { fala (temporal) }\end{array}$ \\
\hline $\begin{array}{l}\text { Choraminga, crises de birra } \\
\text { e barulhento }\end{array}$ & $\begin{array}{lr}\text { Dificuldade } & \text { em } \\
\text { organização } & \text { e } \\
\text { regulação } & \end{array}$ & $\begin{array}{l}\text { Amígdala } \\
\text { Sistema Limbico }\end{array}$ \\
\hline $\begin{array}{l}\text { Mania de querer tudo (fazer } \\
\text { que façam por ele) }\end{array}$ & $\begin{array}{l}\text { Funções executivas } \\
\text { prejudicadas }\end{array}$ & $\begin{array}{l}\text { Córtex pré- } \\
\text { frontal } \\
\text { dorsolateral } \\
\text { Córtex parietal } \\
\text { inferior }\end{array}$ \\
\hline
\end{tabular}




\begin{tabular}{|l|l|l|}
\hline Isola-se, as vezes & Interação social & Córtex pré- \\
& frontal medial \\
& Córtex \\
& temporoparietal \\
& Amigdala \\
\hline
\end{tabular}

Fonte: Própria autora.

As informações da escola, especificamente, da professora em sala de aula apontaram um desempenho distante dos pares (idade) na sala de aula. Criança foi matriculada na pré-escola no ano de 2019 com os seguintes apontamentos realizados por meio do Inventários do ASEBA (Achenbach System of Empirically Based Assessment) especificamente o Inventário de comportamento para crianças - CBCL (C- TRF - 1 e 1/2 a 5 anos) - professores (ACHENBACH, 2010) e Escala de avaliação do comportamento infantil - para professores (EACI-P) (BRITO, 2007). Listados os seguintes comportamentos de acordo com a observação da professora, a saber:

Quadro 2. Apresentação dos comportamentos de Arthur de acordo com a observação da professora.

\begin{tabular}{|l|l|l|}
\hline \multicolumn{1}{|c|}{ Comportamentos } & \multicolumn{1}{|c|}{$\begin{array}{c}\text { Habilidades } \\
\text { prejudicadas } \\
\text { Comporta-se de } \\
\text { maneira infantil para } \\
\text { sua idade; }\end{array}$} & \multicolumn{1}{|c|}{$\begin{array}{c}\text { Áreas cerebrais } \\
\text { requisitadas }\end{array}$} \\
\hline $\begin{array}{l}\text { Não se } \\
\text { conecta/presta } \\
\text { atenção/mundo da } \\
\text { lua; }\end{array}$ & $\begin{array}{l}\text { Tiposial de atenção } \\
\text { (sustentada, } \\
\text { alternada, dividida) }\end{array}$ & $\begin{array}{l}\text { Córtex pré-frontal e } \\
\text { temporopariental }\end{array}$ \\
\hline $\begin{array}{l}\text { Inquietação motora; } \\
\text { temporiental }\end{array}$ & $\begin{array}{l}\text { Tipos de atenção } \\
\text { (sustentada, }\end{array}$ & $\begin{array}{l}\text { Córtex pré-frontal e } \\
\text { temporopariental }\end{array}$ \\
\hline
\end{tabular}

Interfaces da Educ., Paranaíba, v.11, n.31, p. 582 - 605, 2020 


\begin{tabular}{|c|c|c|}
\hline Não suporta esperar & $\begin{array}{l}\text { Função executiva } \\
\text { (controle inibitório) }\end{array}$ & $\begin{array}{l}\text { Cortex pré-frontal } \\
\text { porção anterior; corpo } \\
\text { estriado ventral }\end{array}$ \\
\hline $\begin{array}{l}\text { Apático, mas } \\
\text { desafiador; }\end{array}$ & Cognição social & $\begin{array}{l}\text { Córtex pré-frontal e } \\
\text { temporopariental }\end{array}$ \\
\hline $\begin{array}{l}\text { Quer tudo na hora e } \\
\text { que façam por ele; }\end{array}$ & $\begin{array}{l}\text { Função executiva } \\
\text { (controle inibitório) }\end{array}$ & $\begin{array}{l}\text { Cortex pré-frontal } \\
\text { porção anterior }\end{array}$ \\
\hline $\begin{array}{l}\text { Destrói as coisas dele } \\
\text { (material); }\end{array}$ & $\begin{array}{l}\text { Função executiva - } \\
\text { planejamento } \\
\text { organização, tomada } \\
\text { de decisão }\end{array}$ & $\begin{array}{l}\text { Cortex pré-frontal } \\
\text { porção posterior }\end{array}$ \\
\hline $\begin{array}{l}\text { Dificuldade em seguir } \\
\text { instruções; }\end{array}$ & $\begin{array}{l}\text { Função executiva } \\
\text { (flexibilidade cognitiva } \\
\text { e } \\
\text { operacional) }\end{array}$ & Córtex temporofrontal \\
\hline $\begin{array}{l}\text { Se intromete em } \\
\text { assuntos alheios; }\end{array}$ & $\begin{array}{l}\text { Função executiva } \\
\text { (controle inibitório) }\end{array}$ & $\begin{array}{l}\text { Cortex pré-frontal } \\
\text { porção anterior }\end{array}$ \\
\hline $\begin{array}{l}\text { Comportamentos } \\
\text { imprevisiveis e muda } \\
\text { repentina de humor; }\end{array}$ & $\begin{array}{l}\text { Função executiva } \\
\text { (controle inibitório) }\end{array}$ & $\begin{array}{l}\text { Cortex pré-frontal } \\
\text { ventrolateral; núcleo } \\
\text { mediodorsal do } \\
\text { tálamo e o circuito } \\
\text { límbico-estriatal- } \\
\text { palidal talâmico }\end{array}$ \\
\hline $\begin{array}{l}\text { Movimentos } \\
\text { repetitivos (fica } \\
\text { pulando ao lado da } \\
\text { carteira) com fala } \\
\text { demasiada }\end{array}$ & $\begin{array}{l}\text { Discurso desconexo, } \\
\text { assuntos incoerentes }\end{array}$ & $\begin{array}{l}\text { Cortex relacionados } \\
\text { com processos } \\
\text { auditivo e da fala } \\
\text { (temporal) }\end{array}$ \\
\hline Tem medos (escola) & Interação social & $\begin{array}{l}\text { Córtex pré-frontal } \\
\text { medial }\end{array}$ \\
\hline
\end{tabular}


Sinais comportamentais precoces...

\begin{tabular}{|c|c|c|}
\hline & & $\begin{array}{l}\text { Córtex } \\
\text { temporoparietal } \\
\text { Amígdala }\end{array}$ \\
\hline Sente-se cansado & Sobrecarga, fadiga & Corpo estriado ventral \\
\hline $\begin{array}{l}\text { Dificuldade em } \\
\text { mudar } \\
\text { comportamento; } \\
\text { Dificuldade em } \\
\text { mudanças (hiperfoco) }\end{array}$ & $\begin{array}{l}\text { Função executiva } \\
\text { (flexibilidade cognitiva } \\
\text { e memoria } \\
\text { operacional) }\end{array}$ & Córtex temporofrontal \\
\hline $\begin{array}{l}\text { Grita muito; faz } \\
\text { birras. Choraminga e } \\
\text { barulhento; }\end{array}$ & $\begin{array}{lr}\text { Dificuldade } & \text { em } \\
\text { organização } & \mathrm{e} \\
\text { regulação } & \end{array}$ & $\begin{array}{l}\text { Amígdala } \\
\text { Sistema Límbico }\end{array}$ \\
\hline $\begin{array}{l}\text { Não tem noção do } \\
\text { perigo; }\end{array}$ & $\begin{array}{l}\text { Função executiva } \\
\text { (controle inibitório) }\end{array}$ & $\begin{array}{l}\text { Cortex pré-frontal } \\
\text { porção anterior }\end{array}$ \\
\hline $\begin{array}{l}\text { Fantasias (diz falar } \\
\text { com anjos e vê } \\
\text { fantasmas); }\end{array}$ & $\begin{array}{l}\text { Julgamento (real } \mathrm{x} \\
\text { imaginário) }\end{array}$ & Cortex pré-frontal \\
\hline $\begin{array}{l}\text { Teimoso e irrita-se } \\
\text { facilmente }\end{array}$ & Compreensão & Formação hipocampal \\
\hline $\begin{array}{l}\text { Está bem abaixo da } \\
\text { média da sala; }\end{array}$ & $\begin{array}{l}\text { Desempenho } \\
\text { acadêmico } \\
\text { (aprendizagem; } \\
\text { leitura, escrita } \\
\text { matemática) }\end{array}$ & $\begin{array}{l}\text { Circuitaria } \\
\text { Neuropsicolinguistica } \\
\text { abarcando várias } \\
\text { áreas corticais }\end{array}$ \\
\hline $\begin{array}{l}\text { Tarefas com } \\
\text { exigências cognitivas } \\
\text { mais elaboradas se } \\
\text { recusa a fazer; }\end{array}$ & Cognicão social & $\begin{array}{l}\text { Córtex pré-frontal e } \\
\text { temporopariental }\end{array}$ \\
\hline $\begin{array}{l}\text { Diz falar com pessoas } \\
\text { (imaginárias) }\end{array}$ & $\begin{array}{l}\text { Julgamento (real x } \\
\text { imaginário) }\end{array}$ & Cortex pré-frontal \\
\hline
\end{tabular}

Fonte: Própria autora. 


\section{Resultados}

\section{Apresentação das habilidades prejudicadas em tarefas da intervenção psicopedagógica}

Um fato observado pelos pesquisadores da pesquisa de Maldonado e colaboradores (2018) e que corrobora com a presente pesquisa foi a influência do comprometimento cognitivo sobre a capacidade funcional dos pacientes com transtornos mentais, conseguir manter-se em atividades recreativas, funcionamento social e de situação mesmo em aprendizagens lúdicas. De fato, sugere-se que o desempenho desses pacientes em tarefas de atenção e de memória de trabalho se relacione com aquisição de habilidades executivas.

É mister dizer que foi realizado uma avaliação minuciosa do caso exposto, por conseguinte a análise dos resultados favorecera a construção do programa de intervenção. No entanto, salienta-se que não foi objetivo aqui de explicitar o processo avaliativo, embora sugere-se fortemente que ocorra um delineamento avaliativo bastante robusto para o desenvolvimento e progressão interventiva de qualquer caso.

A descrição do comportamento em formato de adendo, a seguir foi anexada ao relatório principal psicopedagógico com o intuito de oferecer informac,ões sobre o comportamento de Arthur diante das intervencõos realizadas, bem como comportamentos também relatados pela mãe e professora, para o encaminhamento ao médico da área da psiquiatria infantil. No quadro 3 verifica-se habilidades deficitárias observadas e as estratégias desenvolvidas para Arthur. Os resultados estão descritos após o mesmo, juntamente, com as observações realizadas no decorrer das sessões realizadas pela profissional da psicopedagogia.

Quadro 3. Fragmentos do Programa de intervenção psicopedagógica desenvolvido para Arthur nos primeiros trinta dias. 


\begin{tabular}{|c|c|c|c|}
\hline Problema/queixa & $\begin{array}{c}\text { Hipótese que } \\
\text { explica o } \\
\text { problema }\end{array}$ & $\begin{array}{c}\text { Habilidades } \\
\text { em déficit }\end{array}$ & $\begin{array}{c}\text { Técnica/Estratégias } \\
\text { psicopedagógica }\end{array}$ \\
\hline $\begin{array}{l}\text { Não consegue } \\
\text { permanecer na } \\
\text { atividade } \\
\text { proposta }\end{array}$ & $\begin{array}{l}\text { Dificuldade } \\
\text { de atenção e } \\
\text { rastrear os } \\
\text { detalhes na } \\
\text { atividade } \\
\text { proposta }\end{array}$ & $\begin{array}{l}\text { Percepção e } \\
\text { atenção } \\
\text { visual }\end{array}$ & $\begin{array}{l}\text { Sequência lógica e } \\
\text { organizar figuras e } \\
\text { seus pares. } \\
\text { Formação de figuras } \\
\text { analisando suas } \\
\text { partes. } \\
\text { Encontrar o detalhe } \\
\text { ausente na figura e } \\
\text { parear com a } \\
\text { completa. }\end{array}$ \\
\hline $\begin{array}{l}\text { Problemas de } \\
\text { atenção e } \\
\text { concentração e } \\
\text { na formação dos } \\
\text { pensamentos } \\
\text { (falta de lógica) }\end{array}$ & $\begin{array}{l}\text { Programação e } \\
\text { execução lógica } \\
\text { da linguagem. }\end{array}$ & $\begin{array}{l}\text { Linguagem } \\
\text { oral }\end{array}$ & $\begin{array}{l}\text { Criação de histórias } \\
\text { a partir de figuras }\end{array}$ \\
\hline $\begin{array}{l}\text { Muda de } \\
\text { atividade sem } \\
\text { previsão, } \\
\text { acompanhado de } \\
\text { comportamento } \\
\text { ansioso e baixa } \\
\text { tolerância ao } \\
\text { estresse da } \\
\text { atividade; muita } \\
\text { dificuldade em } \\
\text { lembrar das } \\
\text { palavras e coloca- }\end{array}$ & $\begin{array}{l}\text { Anomias, } \\
\text { perifrases, } \\
\text { parafasias, } \\
\text { heminegligencias, } \\
\text { Agramatismo. }\end{array}$ & $\begin{array}{l}\text { Funções } \\
\text { executivas } \\
\text { (controle } \\
\text { inibitório e } \\
\text { memória } \\
\text { operacional) }\end{array}$ & $\begin{array}{l}\text { Nomeação de figuras } \\
\text { de vários grupos } \\
\text { semânticos e sua } \\
\text { classificação em } \\
\text { conjuntos. } \\
\text { Emparelhar objetos } \\
\text { iguais mas não } \\
\text { idênticos. } \\
\text { Emparelhar } \\
\text { associando funções. }\end{array}$ \\
\hline
\end{tabular}




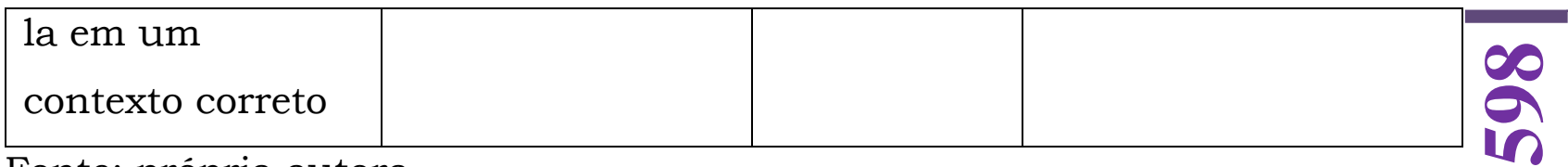

Fonte: própria autora

De acordo com programa psicopedagógico (realizado em um periodo de trinta dias, sessões uma vez na semana com duração de 60 minutos cada) estabelecido foram traçados os seguintes objetivos, os quais eleitos como basilares para aprendizagem da criança: a-) trabalho com percepção visual, pois Arthur como já mencionado nos resultados do relatório apresenta dificuldades para rastrear detalhes de figuras em contextos diversos, a saber: cenas de sequencia lógica, figuras que demonstram ações do cotidiano da criança; b-) atividade linguagem oral e funções executivas, desenvolvimento de eventos com apoio visual, como por exemplo, descrição de acontecimento para formulação de um discurso coerente, ou seja, programação e execução de uma descrição, ou mesmo de uma simples conversa versando ambiente ecológico.

Em relação a percepção visual Arthur apresenta uma dificuldade bastante significativa na organização (mesmo que visual) da sequência lógica, descontextualizando o significado e inserindo na tarefa aglomerações de substantivos sem coerência, bem como a invenção de outra história sobre a sequencia, sem se quer os elementos ditos fazerem parte do contexto da mesma e com associação frouxa de ideias e ambivalencia de posicionamento sobre seu reconto.

Referente as tarefas de linguagem oral e funções executivas Arthur apresenta perseverações de assuntos mórbidos e desconexos da realidade. Parece querer transformar o contexto apontando delírios sobre acontecimentos já ocorridos, mas com certo agravamento destes.

$E^{\prime}$ importante salientar que o seu discurso apresenta uma fala com entonação dispare, ou seja, uma prosódia dissônica (várias nuances sonoras em uma mesma frase).

A progenitora relata dicotomização de significados durante uma conversa informal, ou a inserção de personagens não existentes, mesmo que essa conversa não tenha e nem apresente sentido para a descrição de personagens, como foi a ocasião de uma feitura de tarefa que Arthur iniciou e permaneceu Interfaces da Educ., Paranaíba, v.11, n.31, p. 582 - 605, 2020 
discursando sobre cabeças e corpos seccionados, apresentando também compreensão e fluxo de pensamento com catatonia. Esvaziamento de sentimentos também podem ser observados no contato com o gato da família quando a criança tenta interagir com o animal.

A professora relata que Arthur apresenta uma certa fixação (mania de perseguição) em relação colegas da sala de aula, onde diz que todos o persegue e o exclui das brincadeiras, porém todos gostam dele e o inclui nos afazeres da classe. A educadora também descreve que a criança diz acontecer coisas que não ocorrem no cotidiano escolar, como por exemplo, em relação outra criança (sempre a mesma) dizendo que a mesma é "do mal" e precisa combate-la. Há dias, segundo a professora, que Arthur não quer fazer as atividades, precisando que ela intervenha de forma mais próxima (afetuosa) para conseguir algo. Relata também que nas aulas inicia conversas que fogem da realidade da sala de aula e do contexto da explicação do assunto a ser desenvolvido.

\section{Discussão para implicações práticas na clínica psicopedagógica}

Com base nesse caso clínico, algumas considerações e discussões serão tratadas nesta seção, bem como uma análise dos comportamentos apresentados.

O modelo do caso exposto apoia um modelo de neurodesenvolvimento de acordo com Bora e Murray (2013), em vez de modelos neurodegenerativo e relacionado ao declínico dos transtornos mentais. As evidências disponíveis, apontadas pelos comportamentos precoces do caso sugerem que os déficits nos transtornos psicóticos, em funções executivas, por exemplo, já são evidentes antes do início do primeiro episódio do surto como podemos observar na literatura comentada e relacionada neste caso (ADDINGTON, 2019; DICKSON, 2018).

No entanto, o tempo e as trajetórias desenvolvimentais de anormalidades cognitivas nesses transtornos precisam ser abordados, pois há um aumento relativo das diferenças cognitivas de controle do paciente com a idade. Em uma minoria substancial dos casos, esses déficits se desenvolvem precocemente como moderados, e deficiências intelectuais limítrofes podem ser evidenciadas em muitos individuos com transtornos mentais. Em outros, Interfaces da Educ., Paranaíba, v. 11, n.31, p. 582 - 605, 2020 
as anormalidades cognitivas parecem ser mais sutis e tornam-se evidentes mais tarde no desenvolvimento durante o final da infância e a adolescência. Déficits cognitivos observados na esquizofrenia, por exemplo, parecem ser melhor explicados por problemas na aquisição durante o neurodesenvolvimento.

As observações sistemáticas nos seus contextos, seja ele em contexto de instituição escolar, clínico ou familiar, necessitam ser apontadas como recurso suplementar e também ampliada para compor as informações que conjuntamente construirão o raciocínio clínico do profissional da área psiquiátrica.

Assim, a psicopedagogia (SAMPAIO, 2005; RAMOS, 2019; ALBINO, 2020) como uma área do desenvolvimento da aprendizagem aliado as fundamentações da Neurociências (SOUZA; ALBUQUERQUE, 2018) têm investido esforços na caracterização de mecanismos cognitivos e também na observação de comportamentos subjacentes à heterogeneidade dos transtornos mentais. Sobremaneira, os comportamentos relatados no caso apresentado vêm corroborar com a literatura apontada.

É importante observar em ambos os quadros apresentados os comportamentos cujas habilidades prejudicadas estão relacionadas as funções executivas e áreas de instabilidade do humor. Tal resultado corrobora com os achados de Vismari (2004).

Atualmente, considerando toda a história desenvolvimental e a estimulação oferecida, é possivel afirmar que o seu perfil clínico pode ser classificado de acordo com o modelo proposto por Copeland e colaboradores (2009) no qual é caracterizado por falhas na compreensão, especificamente, vocabulário expressivo; na falta de coerência do seu discurso, apontamentos de comportamentos de delírios, bem como manias persecutórias somada as dificuldades cognitivas que culminam em atrasos acadêmicos e sociais de acordo com Condry (2003).

\section{Considerações finais}

A observação em relação aos comportamentos precoces na infância torna-se um elemento essencial para um período no qual diversas habilidades Interfaces da Educ., Paranaíba, v.11, n.31, p. 582 - 605, 2020 
estão sendo adquiridos e no qual o cérebro é potencialmente mais plástico (sofre maior influência de experiências e do ambiente), principalmente em áreas responsáveis por funções complexas. Esse portanto é um período de extrema importância para a estimulação da criança e para a intervenção precoce nos transtornos mentais.

Em relação ao desenvolvimento cognitivo, as funções executivas, por sua importância em direção aos desfechos funcionais associados, tem sido foco de construção de estratégias de intervenção e melhoramento, em geral. Intervenções comportamentais são indicadas para estimular habilidades especificas e controlar de maneira consciente o comportamento da criança, evitando aqueles inadequados ou disruptivos e fortalecendo os comportamentos desejados.

Neste texto foi apresentado um caso e relatado sintomas comportamentais precoces de um caso suspeito de transtorno psicótico na infância, cujos comportamentos foram descritos a fim de auxiliar no desenvolvimento do perfil e colaborar para um futuro diagnóstico.

Portanto, pais e professores devem ficar atentos ao comportamento da criança e a possiveis atrasos em seu desenvolvimento, procurando auxilio profissional sempre que necessário.

\section{Referências}

ACHENBACH, T. M. ASEBA: Achenbach system of empirically based assessment. http://www. aseba. org/, 2010.

ADDINGTON, J. et al. Predictors of Transition to Psychosis in Individuals at Clinical High Risk. Current psychiatry reports, v. 21, n. 6, p. 39, 2019.

ALBINO, A. et al. Análise em grupo com pacientes psicóticos: a experiência do "grupo vida". Revista Família, Ciclos de Vida e Saúde no Contexto Social, v. 8, n. $1,2020$.

BORA, E. Neurodevelopmental origin of cognitive impairment in schizophrenia. Psychological Medicine, v. 45, n. 1, p. 1-9, 2015. Interfaces da Educ., Paranaíba, v.11, n.31, p. 582 - 605, 2020 
BORA, E.; MURRAY, R. M. Meta-analysis of cognitive deficits in ultra-high risk to psychosis and first-episode psychosis: do the cognitive deficits progress over, or after, the onset of psychosis? Schizophrenia bulletin, v. 40, n. 4 , p. $744-755,2013$.

BRITO, G. N. O. EACI-P. Escala de avaliação do comportamento infantil para o professor: manual. São Paulo: Vetor, 2007.

BUTLER, P.; SCHECHTER, I.; ZEMON, V. et al., Dysfunction of early stage visual processing in schizophrenia, Am. J. Psychiatry 158: 2001, 11261133.

CONDRAY, R. et al. The language system in schizophrenia: Effects of capacity and linguistic structure. Schizophrenia Bulletin, v. 28, n. 3, p. 475490, 2002.

CONDRAY, Ruth et al. Automatic activation of the semantic network in schizophrenia: evidence from event-related brain potentials. Biological Psychiatry, v. 54, n. 11, p. 1134-1148, 2003.

CONDRAY, R.; GLASGOW, A. G. The relationship between membrane pathology and language disorder in schizophrenia. Behavioral and Brain Sciences, v. 69, n. 6, p. 449-460, 2003. (a)

CONDRAY, R.; STEINHAUER, S. R. Mechanisms of disrupted language comprehension in schizophrenia. Behavioral and Brain Sciences, v. 26, n. 1, p. 87-88, 2003. (b)

COPELAND, W. E. et al. Childhood and adolescent psychiatric disorders as predictors of young adult disorders. Archives of general psychiatry, v. 66, n. 7, p. 764-772, 2009. 
COSTA, D. S.; MALLOY-DINIZ, L. F.; MIRANDA, D. M. Genética e desenvolvimento humano. IN: MIRANDA, D. M.; MALLOY-DINIZ, L. F. O pré-escolar. São Paulo: Hogrefe, 2018.

DIAS, N. M.; SEABRA, A. G. (Org.) Neuropsicologia com pré-escolares: avaliação e intervenção. São Paulo: Pearson, 2018.

DICKSON, H. et al. Trajectories of cognitive development during adolescence among youth at-risk for schizophrenia. Journal of Child Psychology and Psychiatry, v. 59, n. 11, p. 1215-1224, 2018.

DRIVER, D. I. et al. Childhood-Onset Schizophrenia and Early-onset Schizophrenia Spectrum Disorders: An Update. Child and Adolescent Psychiatric Clinics, v. 29, n. 1, p. 71-90, 2020.

GOULDING, S. M. et al. The prodrome and clinical risk for psychotic disorders. Child and Adolescent Psychiatric Clinics, v. 22, n. 4, p. 557-567, 2013.

GREEN, M.F.; NUECHTERLEIN, K.H.; MINTZ, J. Backward masking in schizophrenia and mania: II. Specifying the visual channels, Arch. Gen. Psychiatry. v. 51, p. 945-951, 1994.

KARAYIORGOU, M.; SIMON, T. J.; GOGOS, J. A. 22q11. 2 microdeletions: linking DNA structural variation to brain dysfunction and schizophrenia. Nature Reviews Neuroscience, v. 11, n. 6, p. 402, 2010.

LARSON, M. K.; WALKER, E. F.; COMPTON, M. T. Early signs, diagnosis and therapeutics of the prodromal phase of schizophrenia and related psychotic disorders. Expert review of neurotherapeutics, v. 10, n. 8, p. 1347-1359, 2010. 
MACCOBY, E. E. Parenting and its effects on children: On reading and misreading behavior genetics. Annual review of psychology, v. 51, n. 1, p. 1$27,2000$.

MALDONADO, M. G et. al. Esquizofrenia paranoide. In: MONTORO, M.; SERRANO, J. B.; MOSQUERA, M. T. (org) Neuropsicologia através de casos clínicos. Pindamonhangaba: Coletivo Editorial - CEPSIC, 2018.

PINE, D. S.; FOX, N. A. Childhood antecedents and risk for adult mental disorders. Annual Review of Psychology, v. 66, p. 459-485, 2015.

RAMOS, B. R. Diferenças entre descendentes de pais bipolares e descendentes de pais não bipolares em uma amostra de pacientes com transtorno bipolar pediátrico. 2019.

RIECHER-RÖSSLER, A.; STUDERUS, E. Prediction of conversion to psychosis in individuals with an at-risk mental state: a brief update on recent developments. Current opinion in psychiatry, v. 30, n. 3, p. 209-219, 2017.

ROCHA, M. M.; TAFLA, T. L.; TEIXEIRA, M. C. T. V. Avaliacão de problemas de comportamento na idade pré-escolar. In: DIAS, N. M.; SEABRA, A. G. Neuropsicologia com pré-escolares: avaliação e intervenção. São Paulo: Pearson, 2018.

SAMPAIO, C. P. A clínica dos transtornos autísticos e psicóticos na adolescência e a perspectiva da inclusão ou da recomposição necessária do mundo. I Simpósio Internacional do Adolescente, maio, 2005.

SANTANA; C. V. N.; SOUZA, R. P. Epigenética e desenvolvimento humano. In: MIRANDA, D. M.; DINIZ-MALOY, L. F. O pré-escolar. São Paulo: Hógrefe, 2018. 
SIGELMAN, C. K.; RIDER, E. A. Life-span human development. Cengage Learning, 2014.

SOUZA, A. K. V; ALBUQUERQUE, M. R. O efeito da idade relativa e o desenvolvimento no pré-escolar. In: MIRANDA, D. M.; DINIZ-MALOY, L. F. O pré-escolar. São Paulo: Hógrefe, 2018.

VISMARI, L. Neuroanatomia dos transtornos de humor. Conscientiae Saúde, n. 3, p. 95-102, 2004. 